\title{
Anxiety Level in Pre-hospital Emergency Medical Services Personnel During Coronavirus Disease-2019 Pandemic
}

\author{
(D) Hüseyin Mutlu, (D) Ekrem Taha Sert, (D) Kamil Kokulu, (D) Ayhan Sarıtaș \\ Department of Emergency Medicine, Aksaray University Faculty of Medicine, Aksaray, Turkey
}

\begin{abstract}
Aim: This study aimed to determine the anxiety level in pre-hospital emergency medical services personnel (PHEMSPS) and investigate the factors that potentially affect the anxiety level during the pandemic.

Materials and Methods: This cross-sectional survey was conducted with PHEMSPs during the Coronavirus Disease-2019 (COVID-19) pandemic. A 60-item survey, including socio-demographic characteristics, anxiety-related demographic factors, and State-Trait Anxiety Inventory (STAI) scale scores was used.

Results: Among 586 PHEMSPs participating in the study, 50.5\% were female, with median age of 30 years. The mean STAI-S value was 42.2 , and the median STAI-T value was 48. The anxiety levels of female PHEMSPs (STAI-S=51 and STAI-T=44.14) were higher than male (STAI-S=44 and, STAI-T=40.26). The anxiety level of patients with chronic diseases (STAI-S=56 and, STAI-T=45.77) was significantly higher than those without chronic diseases. State anxiety scores in married individuals (STAI-S=49) were higher than those unmarried individuals.

Conclusion: Clearly, people who provide this service should be psychologically healthy to efficiently provide healthcare for the benefit of the people. All types of media assume a great responsibility in reducing the unrest or anxiety that may occur in humans, especially because of their potential to reach many parts of the society.

Keywords: STAI, SARS CoV-2, outbreak
\end{abstract}

\section{Introduction}

In December 2019, cases of pneumonia of unknown cause emerged in Wuhan, Hubei, China (1). A new type of coronavirus, severe acute respiratory syndrome coronavirus 2 (SARS-COV-2) had been identified as the etiological agent causing pneumonia (2). Although this new type of coronavirus was first seen only in China, it has rapidly spread across the world, especially in countries in the continents of Europe and America, and the World Health Organization has defined this outbreak as the coronavirus disease-19 (COVID-19) pandemic.

As the number of infections increased, the lack of precise information about the virus in the media and the thought that currently available resources may be insufficient caused intense anxiety among health care workers $(3,4)$. Faced with this large- scale infectious public health incident, health workers have been under both physical and psychological stress (5).

Prehospital emergency medical services personnel (PHEMSPs) are a community that provides service $24 / 7$. They have crucial highrisk duties and responsibilities that involve intensive work rates, and they work under pressure and stress (6). The incidence of mortality, fatal accidents and injuries, musculo skeletal system complications, anxiety, and sleep problems were found to be higher in PHEMSPs than in other health care workers (7).

To the best of our knowledge, no study has measured the level of anxiety in PHEMSPs during the COVID-19 pandemic. This study was performed to determine the level of anxiety in PHEMSPS during the pandemic. In addition, this study aimed to investigate factors that potentially affect the level of anxiety, such as age, concomitant chronic disease, marital status, and child status. 


\section{Materials and Methods}

This cross-sectional survey was conducted with PHEMSPs working in Aksaray and Konya during the COVID-19 pandemic (from April $21^{\text {st }}, 2020$ to April $27^{\text {th }}, 2020$ ). The study was approved by the Local Ethics Committee of Aksaray University Human Researches (no: 2020-03/54, date: 24.04 .2020 ) and the Ministry of Health of the Republic of Turkey (2020-05-13T13_55_01). A total of 1357 PHEMSPs are currently performing their duties; 278 are employed in Aksaray and 1,079 in Konya. Participation in the study was voluntary, and 586 PHEMSPs who completed the questionnaire participated in the study. Data was collected via an online survey over the Internet. PHEMSPs who agreed to participate in the study were sent a link through social media (WhatsApp, Twitter, and Facebook) and were asked to complete the survey. Participants were allowed to drop out of the study at any time. The survey was anonymous and information kept confidential. Participants were instructed to complete the survey and answer all questions. The survey comprised 60 items including sociodemographic characteristics (age, gender, marital status, child status, living with family, education level, and occupational status), health, social and demographic factors that are thought to be related to anxiety (smoking, presence/absence of chronic diseases, whether the workplace measures are adequate, workplace satisfaction, and compliance with measures taken for the pandemic), and State-Trait Anxiety Inventory (STAI) scale scores.

The STAI consists of two parts, each with 20 questions. While the stateanxiety (STAI-S) scale aims to measure anxiety at a given time, the trait anxiety (STAI-T) scale measures long-term anxiety levels. All items are evaluated using a 4-point Likert scale. There are 10 reversed phrases inSTAI-S and 7 in STAI-T. In the evaluation process, points between 1 and 4 were scored as negative (reducing the total anxiety score) or positive (increasing the total anxiety score) according to the selected option. As a constant value, 50 for the STAI-S and 35 for the STAI-T were added to the obtained scores. The most recent value obtained was taken as the anxiety score of the individual. Accordingly, the highest value was 80 and the lowest value was 20. Values of 20-35 indicated little anxiety, 36-41 indicated moderate anxiety, and 42-80 indicated high anxiety. The State-Trait Anxiety Inventory (STAI FORM TX1, TX-2) was developed by Spielberger et al. Turkish validity and reliability of the scale was performed by Öner and Le Comte (8).

\section{Statistical Analysis}

All statistical analyses were performed using SPSS version 15.0 for Windows (SPSS Inc., Chicago, IL, USA). Among the trait variables, those that were normally distributed were presented as the average \pm standard deviation and those that were non-normally distributed were presented as the median (interquartile range).
The compatibility of trait variables to normal distribution was evaluated using the Kolmogorov-Smirnov test. Categorical data was expressed as $\mathrm{n}(\%)$. In the comparison of the trait data between the two groups, the Mann-Whitney $\mathrm{U}$ test was used for non-normally distributed trait data and independent sample t-test was used for normally distributed trait data. The chi-square test or Fisher's exact test (as applicable) was used to compare categorical variables. In the comparison of the trait variables among three groups, One-Way analysis of variance was used for normally distributed trait data and the Kruskal-Wallis $\mathrm{H}$ test was used for non-normally distributed trait data. Posthoc Bonferroni correction was used for subgroup comparisons. The relationship between age, working time, and number of suspected patients evaluated daily and anxiety scale scores were evaluated using Spearman correlation.

\section{Results}

Among 586 PHEMSPs participatingin the study, 49.5\% $(n=290)$ were male and $50.5 \%(n=296)$ were female, and the median age was 30 (25-36) years. Two hundred and eighty-seven (49.0\%) PHEMSPs were emergency medical technicians and 196 (33.4\%) were paramedics. In addition, 423 (72.2\%) lived with their family, whereas 163 (27.8\%) consisted of those who would live separately from their family during the pandemic. The mean STAI-S value of PHEMSPS was $42.2 \pm 8.6$, and the median STAI-T value was 48 (39-56). The distribution of participants according to sociodemographic and professional characteristics is given in Table 1.

The anxiety levels of female PHEMSPs (STAI-S=51 (44.25-57.0), STAI-T $=44.14 \pm 8.15)$ were higher than those of male PHEMSPS [STAI-S $=44$ (35-52), STAI- $\mathrm{T}=40.26 \pm 8.62](p<0.001)$. The anxiety level of patients with chronic diseases (STAI-S=56 (49.2559.0), STAI-T $=45.77 \pm 8.31$ ) was significantly higher than those without chronic diseases $(p<0.001)$. State anxiety scores in married individuals [STAI- $\mathrm{S}=49(40-57)$ ] were higher than those in unmarried individuals $(p=0.03)$. The distribution of anxiety scores according to sociodemographic characteristics is shown in Table 2.

There was no statistically significant relationship between STAI-S scores and participant age $(r=0.032, p=0.45)$. There was also no statistically significant relationship between STAI-T scores and participant age $(r=0.01, p=0.82)$. There was no statistically significant relationship between the participants' working time and the STAI-S and STAI-T scores $(r=0.067, p=0.11$ and $r=-0.02, p=0.64$, respectively). There was a significant, positive, weak correlation between the STAI-S score and the number of suspected patients assessed daily $(r=0.243, \quad p<0.001)$. 


\begin{tabular}{|c|c|}
\hline \multicolumn{2}{|l|}{ Variables } \\
\hline Age, year, median (IQR) & $30(25-36)$ \\
\hline \multicolumn{2}{|l|}{ Gender, n (\%) } \\
\hline Male & $290(49.5 \%)$ \\
\hline Female & $296(50.5 \%)$ \\
\hline \multicolumn{2}{|l|}{ Marital status, n (\%) } \\
\hline Married & $387(66.0 \%)$ \\
\hline Unmarried & $199(34.0)$ \\
\hline \multicolumn{2}{|l|}{ Child status, n (\%) } \\
\hline Yes & $343(58.5 \%)$ \\
\hline No & $243(41.5 \%)$ \\
\hline \multicolumn{2}{|l|}{ Living with the family } \\
\hline Yes & $423(72.2 \%)$ \\
\hline No & $163(27.8)$ \\
\hline \multicolumn{2}{|l|}{ Occupation } \\
\hline Physician & $14(2.4 \%)$ \\
\hline Paramedic & $196(33.4 \%)$ \\
\hline Emergency medical technician & $287(49.0 \%)$ \\
\hline Nursing & $27(4.6 \%)$ \\
\hline Driver & $42(7.2 \%)$ \\
\hline Another & $20(3.4 \%)$ \\
\hline \multicolumn{2}{|l|}{ Smoking } \\
\hline Never used & $276(47.1 \%)$ \\
\hline Used and left & $95(16.2 \%)$ \\
\hline Actively using & $214(36.5 \%)$ \\
\hline $\begin{array}{l}\text { Number of COVID-19 suspected patients } \\
\text { evaluated daily median (IQR) }\end{array}$ & $3(2-5)$ \\
\hline \multicolumn{2}{|l|}{ Chronic disease } \\
\hline Yes & $48(8.2 \%)$ \\
\hline No & $538(91.8 \%)$ \\
\hline State anxiety score, median (IQR) & $48(39-56)$ \\
\hline Trait anxiety score, mean \pm SD & $42.2 \pm 8.6$ \\
\hline \multicolumn{2}{|c|}{$\begin{array}{l}\text { IQR: Interquartile range, COVID-19: Coronavirus disease-19, SD: Standard deviation, } \\
\text { n: Number }\end{array}$} \\
\hline
\end{tabular}

Furthermore, a significant, positive, very weak correlation was found between the STAI-T score and the number of suspected patients evaluated daily $(r=0.086, p<0.04)$.

The STAI-S and STAI-T scores of the participants were significantly different among groups formed according to their compliance with measures taken due to the pandemic $(p<0.001)$ (Table 3).

\section{Discussion}

As of April 21 ${ }^{\text {st }}, 2020$, the initiation date of our study, the total number of cases in Turkey was reportedly 95,591 and the number of deaths was 2,259 (9). We believed that the increase in the number of cases and deaths would increase the level of anxiety in healthcare workers as well as in the entire community. In this study, we observed that the anxiety level of PHEMSPs during the COVID-19 pandemic had increased; in addition, the anxiety levels in women, those who have children, those with chronic diseases, those living with their family, and those who do not comply with the measures taken due to the COVID-19 pandemic have increased further. In the COVID-19 pandemic, the frontline unit is undoubtedly PHEMSPS. Therefore, their anxiety levels are considered to be high.

In healthcare workers, psychological conditions such as anxiety and symptoms of depression, insomnia, denial, anger, and fear as well as post-traumatic stress disorder increase during pandemics or infectious disease outbreaks (10-12). Studies conducted during outbreaks such as the severe acute respiratory syndrome (SARS) and $\mathrm{H} 1 \mathrm{~N} 1$ revealed depression in $3.7 \%$ of all individuals and $9.6 \%$ of those affected by infection (13). In another study, 17.3\% of healthcare workers who were actively working in hospitalized services of patients with SARS during the SARS outbreak reported mental symptoms $(14,15)$.

The COVID-19 pandemic has caused increased fear across the world. Not knowing when the pandemic will end, not knowing the exact method of treatment, constant changes in information in the press about its effects, suggestions to stay at home during the pandemic, and the decline in social relations have negatively affected everyone's mental health (16).

The fact that health workers who are directly involved in the diagnosis, treatment, and care of patients with COVID-19 have close contact with infected patients results in fear, affective disorders, sleep problems, psychological adaptation, and similar concerns about mental health, such as depression and anxiety $(17,18)$. Kang et al. (5) reported that the anxiety levels of healthcare workers that work in Wuhan has increased due to overwork, high risk of infection, isolation, inability to meet with family, and discrimination. Styra et al. (19) reported that in hospital employees working in Toronto during the SARS epidemic had increased anxiety levels and post-traumatic stress disorder. However, they reported that this increase was less in those who cared for patients with SARS compared with that in those who did not. Similar to findings reported in the literature, we found that PHEMSPs who were the first to contact patients with COVID-19 had high state and trait anxiety levels.

In our study, the state and trait anxiety levels in female PHEMSPS were higher than those in male PHEMSPs, which suggests that the psychiatric effect of COVID-19 are greater in female healthcare workers. Alexander et al. (20) have previously shown that anxiety 


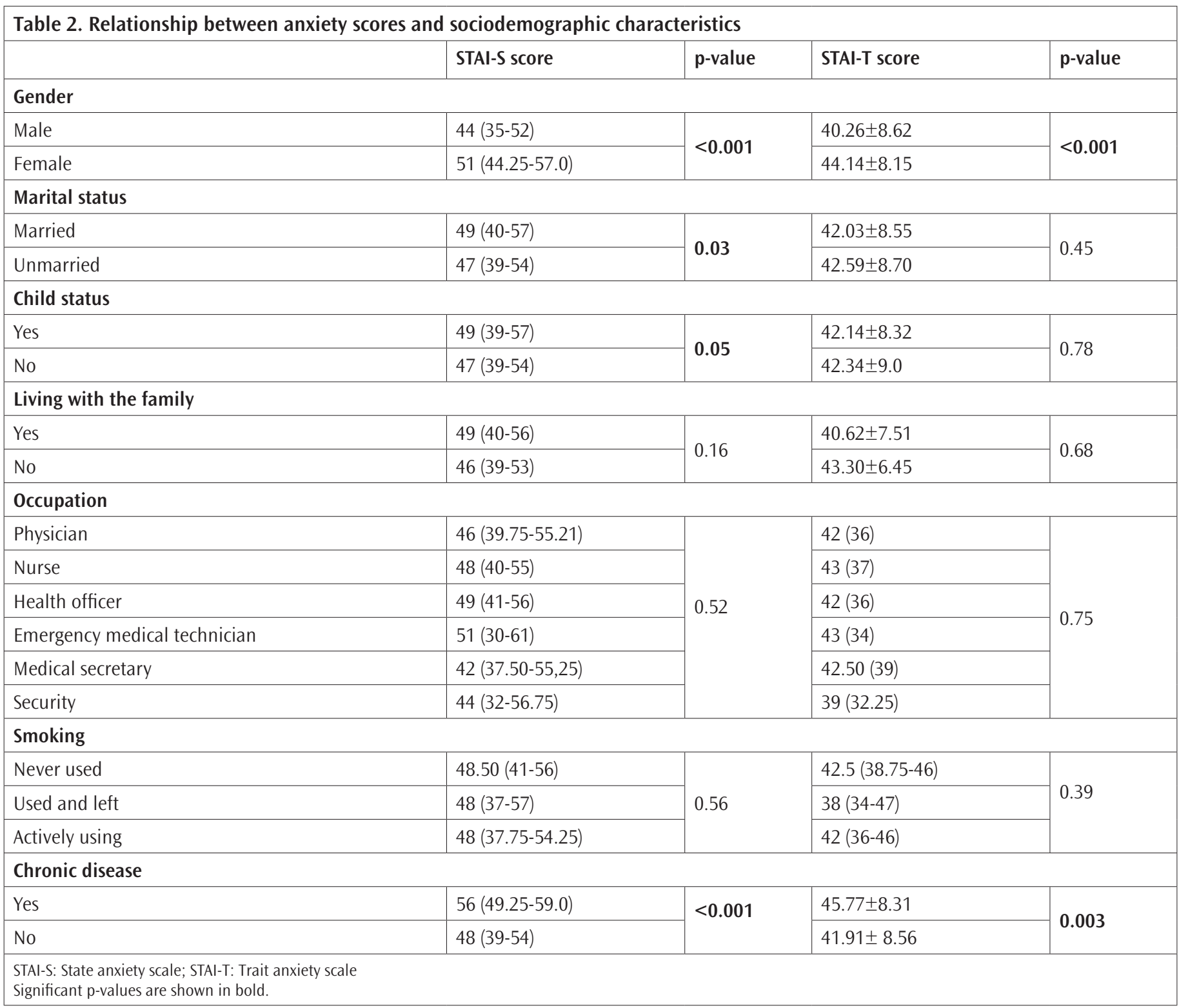

disorders and depressive disorders are more common in women. Many studies have shown that female PHEMSPs have a higher level of anxiety than men $(21,22)$. Anxiety disorder was found to be three times higher in women than in men during the COVID-19 pandemic (4). Liu et al. (23) reported that female gender is the most important determinant of post-traumatic stress disorder after the COVID-19 pandemic in China. As with all these studies and our study, the level of anxiety in women is higher than that in men.

Studies show that patients with COVID-19 with comorbidities have poor prognosis (24). Zhou et al. (25) reported that advanced age and concomitant chronic diseases are the most important risk factors for COVID-19 mortality. Additionally, the risk of developing the disease increases in patients with chronic diseases (26). In our study, we found that the level of anxiety was higher in PHEMSPS with chronic diseases than in those who did not have chronic diseases. Visual and printed media, including social media, have reported that those with chronic diseases have a higher risk of contracting COVID-19 and that the course of the disease may be poor. We believe that such explanations contribute to increased anxiety levels in patients with chronic diseases.

\section{Study Limitations}

The present study has several limitations: those who did not have access to the internet and could not use a smart phone were not included. There was a selection bias: because the survey was completed online, the pre-pandemic levels of anxiety in PHEMSPS who filled the survey were unknown. Another limitation was the small number of cases for a disease affecting the entire world. An 


\begin{tabular}{|c|c|c|c|c|c|}
\hline $\begin{array}{l}\text { Compliance with the COVID-19 related } \\
\text { measures }\end{array}$ & n (\%) & STAI-S score & p-value & STAI-T score & p-value \\
\hline Incompatible & $2(0.3 \%)$ & $59.5(54-65)$ & \multirow{4}{*}{$<0.001$} & $41.5(38-45)$ & \multirow{4}{*}{$<0.001$} \\
\hline Somewhat compliant & $30(5.1 \%)$ & $55(49-60)$ & & $47(42.5-49.5)$ & \\
\hline Very compliant & $184(31.4 \%)$ & $50(43-56.75)$ & & $43(39-49)$ & \\
\hline Completely compliant & $370(63.1 \%)$ & $47(36.75-54)^{1,2}$ & & $41(35-47)^{3,4}$ & \\
\hline \multicolumn{6}{|c|}{$\begin{array}{l}\text { STAI-S: State anxiety scale; STAI-T: Trait anxiety scale, } n \text { : Number } \\
\text { 'There is a statistically significant difference when compared with somewhat compliant group (corrected } p=0.001 \text { ) } \\
\text { 'There is a statistically significant difference when compared with very compliant group (corrected } p=0.006 \text { ) } \\
\text { 'There is a statistically significant difference when compared with somewhat compliant group (corrected } p=0.004 \text { ) } \\
\text { }{ }^{4} \text { There is a statistically significant difference when compared with very compliant group (corrected } p=0.01 \text { ) }\end{array}$} \\
\hline
\end{tabular}

advantage of this study is that it is the first study to measure the anxiety level of PHEMSPs during the pandemic.

\section{Conclusion}

It is obvious that people who provide this service should be psychologically healthy so that people can benefit from healthcare provision more efficiently. This is even more important in pandemics, during which the need for healthcare workers reaches a peak. All types of media assume a great responsibility in reducing the unrest or anxiety that may occur in humans, especially because of their potential to reach many parts of the society.

\section{Ethics}

Ethics Committee Approval: The study was approved by the Local Ethics Committee of Aksaray University Human Researches (no: 2020-03/54, date: 24.04.2020) and the Ministry of Health of the Republic of Turkey (2020-05-13T13_55_01).

Informed Consent: It was obtained.

Peer-review: Externally peer-reviewed.

\section{Authorship Contributions}

Surgical and Medical Practices: H.M., K.K., A.S., Concept: H.M., E.T.S., K.K., Design: H.M., E.T.S., Data Collection or Processing: H.M., K.K., A.S., Analysis or Interpretation: H.M., E.T.S., K.K., Literature Search: H.M., E.T.S., K.K., A.S., Writing: H.M., K.K., A.S.

Conflict of Interest: No conflict of interest was declared by the authors.

Financial Disclosure: The authors declared that this study received no financial support.

\section{References}

1. Wang C, Horby PW, Hayden FG, Gao GF. A novel coronavirus outbreak of global health concern (published correction appears in Lancet. 2020 Jan 29). Lancet. 2020;395:470-3.
2. Zhu N, Zhang D, Wang W, Li X, Yang B, Song J, et al. A Novel coronavirus from patients with pneumonia in China, 2019. N Engl J Med. 2020;382:727-33.

3. Chen N, Zhou M, Dong X, Qu J, Gong F, Han Y, et al. Epidemiological and clinical characteristics of 99 cases of 2019 novel coronavirus pneumonia in Wuhan, China: a descriptive study. Lancet. 2020;395:507-13.

4. Wang Y, Di Y, Ye J, Wei W. Study on the public psychological states and its related factors during the outbreak of coronavirus disease 2019 (COVID-19) in some regions of China (published online ahead of print, 2020 Mar 30). Psychol Health Med. 2020;1-10.

5. Kang L, Li Y, Hu S, Chen M, Yang C, Yang B, et al. The mental health of medical workers in Wuhan, China dealing with the 2019 novel coronavirus. Lancet Psychiatr. 2020;7(3):e14.

6. Wright KP Jr, Bogan RK, Wyatt JK. Shift work and the assessment and management of shift work disorder (SWD). Sleep Med Rev. 2013;17:41-54.

7. Sterud T, Ekeberg $\varnothing$, Hem E. Health status in the ambulance services: a systematic review. BMC Health Serv Res. 2006;6:82.

8. Öner N, Le Compte A. Süreksiz Durumluluk/Sürekli Kaygı Envanteri El Kitabı. 1. Baskı, İstanbul: Boğaziçi Üniversitesi Yayınları, 1983.p.1-26.

9. Republic of Turkey Ministry of Health. (2020). Available at: https://covid19. saglik.gov.tr/

10. Taylor MR, Agho KE, Stevens G], Raphael B. Factors influencing psychological distress during a disease epidemic: data from Australia's first outbreak of equine influenza. BMC Public Health. 2008;8:347.

11. Lau JT, Yang X, Pang E, Tsui HY, Wong E, Wing YK. SARS-related perceptions in Hong Kong. Emerg Infect Dis. 2005;11:417-24.

12. Lee AM, Wong JG, McAlonan GM, Cheung V, Cheung C, Sham PC, et al. Stress and psychological distress among SARS survivors 1 year after the outbreak. Can J Psychiatr. 2007;52:233-40.

13. Ko CH, Yen CF, Yen JY, Yang MJ. Psychosocial impact among the public of the severe acute respiratory syndrome epidemic in Taiwan. Psychiatry Clin Neurosci. 2006;60:397-403.

14. Lu YC, Shu BC, Chang YY, Lung FW. The mental health of hospital workers dealing with severe acute respiratory syndrome. Psychother Psychosom. 2006;75:370-5

15. Wu P, Fang Y, Guan Z, Fan B, Kong J, Yao Z, et al. The psychological impact of the SARS epidemic on hospital employees in China: exposure, risk perception, and altruistic acceptance of risk. Can J Psychiatr. 2009;54:302-11.

16. Özdin S, Bayrak Özdin \$̦. Levels and predictors of anxiety, depression and health anxiety during COVID-19 pandemic in Turkish society: The importance of gender (published online ahead of print, 2020 May 8). Int J Soc Psychiatr. 2020;20764020927051.

17. Asmundson GJG, Taylor S. How health anxiety influences responses to viral outbreaks like COVID-19: What all decision-makers, health authorities, and health care professionals need to know. J Anxiety Disord. 2020;71:102211. 
18. Taylor S, editor. The Psychology of Pandemics: Preparing for the Next Global Outbreak of Infectious Disease. Cambridge Scholars Publishing, 2019.

19. Styra R, Hawryluck L, Robinson S, Kasapinovic S, Fones C, Gold WL. Impact on health care workers employed in high-risk areas during the Toronto SARS outbreak. J Psychosom Res. 2008;64:177-83.

20. Alexander JL, Dennerstein L, Kotz K, Richardson G. Women, anxiety and mood: a review of nomenclature, comorbidity and epidemiology. Expert Rev Neurother. 2007;7(11 Suppl):S45-58

21. Kızıl M, Üstünkarlı N, Erginer DK. İzmir 112 ambulanslarında çalıșan paramedic ve acil tıp teknisyenlerinin anksiyete düzeyleri ve iş stresörleri. Hastane Öncesi Derg. 2016;1:43-54.

22. Svensson A, Fridlund B. Experiences of and actions towards worries among ambulance nurses in their professional life: a critical incident study. Int Emerg Nurs. 2008;16:35-42.
23. Liu N, Zhang F, Wei C, Jia Y, Shang Z, Sun L, et al. Prevalence and predictors of PTSS during COVID-19 outbreak in China hardest-hit areas: Gender differences matter. Psychiatry Res. 2020;287:112921.

24. Wang D, Hu B, Hu C, Zhu F, Liu X, Zhang J, et al. Clinical Characteristics of 138 Hospitalized Patients With 2019 Novel Coronavirus-Infected Pneumonia in Wuhan, China (published online ahead of print, 2020 Feb 7). JAMA 2020;323:1061-9.

25. Zhou F, Yu T, Du R, Fan G, Liu Y, Liu Z, et al. Clinical course and risk factors for mortality of adult inpatients with COVID-19 in Wuhan, China: a retrospective cohort study (published correction appears in Lancet. 2020;395:1038; Lancet. 2020;395:1054-62.

26. Wang B, Li R, Lu Z, Huang Y. Does comorbidity increase the risk of patients with COVID-19: evidence from meta-analysis. Aging (Albany NY). 2020;12:6049-57. 